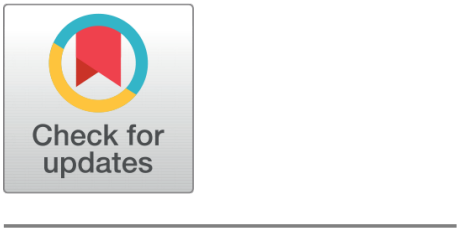

G OPEN ACCESS

Received: 31.05 .2021

Accepted: 17.06 .2021

Published: 18.07.2021

Citation: Rai A, Kumbhar DG, Sutar KB (2021) Computational Investigation on Natural Convection Heat Transfer in Vertical Plate Fin Arrays. Indian Journal of Science and Technology 14(24): 2069-2080. https://doi.org/

10.17485/IJST/v14i24.863

* Corresponding author.

kbsutar@bvucoep.edu.in

Funding: None

Competing Interests: None

Copyright: (c) 2021 Rai et al. This is an open access article distributed under the terms of the Creative Commons Attribution License, which permits unrestricted use, distribution, and reproduction in any medium, provided the original author and source are credited.

Published By Indian Society for Education and Environment (iSee)

ISSN

Print: 0974-6846

Electronic: 0974-5645

\section{Computational Investigation on Natural Convection Heat Transfer in Vertical Plate Fin Arrays}

\author{
Anjali Rai ${ }^{1}$, Dnyaneshwar G Kumbhar ${ }^{1}$, Kailasnath B Sutar ${ }^{1 *}$ \\ 1 Department of Mechanical Engineering, College of Engineering, Bharati Vidyapeeth \\ (Deemed to be University), Pune, India
}

\section{Abstract}

Objectives: To perform computational studies on different combinations of plate fin arrays of different shapes for studying their performance in natural convection heat transfer. To compare the heat transfer performance of uniform notched fins with hybrid notched fins and also performance of normal notched fins with inverted notched fins. Methods: SolidWorks Flow Simulation software is used for the present computational studies. Three types of vertical plate fin arrays viz. plain rectangular fin, rectangular fin with square notch and rectangular fin with semi-circular notch are used with their seven combinations. These fin array combinations are: plain rectangular, rectangular square notched, rectangular semi-circular notched, rectangular inverted square notched, rectangular inverted semi-circular notched, hybrid rectangular square-semi-circular notched and hybrid rectangular inverted square-semi-circular notched. Findings: The highest average heat transfer coefficient of $7.82 \mathrm{~W} / \mathrm{m}^{2} \mathrm{~K}$ is found to be for inverted hybrid square-semicircular notched fin array. This value of heat transfer coefficient is about $8 \%$ higher than compared to that with plain rectangular plate fin array $\left(7.25 \mathrm{~W} / \mathrm{m}^{2} \mathrm{~K}\right)$ subjected to same operating conditions. Average heat transfer coefficients for inverted plate fin array combinations are high as compared with the non-inverted combinations. Also, hybrid plate fin arrays, whether inverted or not, show higher heat transfer coefficient values as compared with uniform notched fin arrays. Novelty : Seven types of plate fin array combinations are studied computationally. SolidWorks Flow Simulation software is used very effectively for this 3D CFD analysis. The behaviour of fluid i.e. air during natural convection flow is studied using air flow velocity trajectories. Surface contours are effectively used for studying variation in surface temperature and heat transfer coefficient at all locations of fin arrays.

Keywords: Natural convection; plate fin array; heat transfer coefficient; CFD; heat transfer enhancement 


\section{Introduction}

Cooling of electronic devices has drawn more attention of the researchers due to their increased use in almost all technological advancements. Researchers across the globe are working on different configurations of fins for heat transfer enhancement especially in natural convection process. It is observed that fins with notches give the best results reducing the cost of material and increasing the convective heat transfer rate. Heat transfer enhancement techniques have been extensively developed to improve the thermal performance of heat exchanger systems with a view to reducing the size and cost of the systems.

Basim Freegah et al. ${ }^{(1)}$ studied transfer enhancement in plate-fin heat sinks with fillet profile using six different geometries of heat sink. The authors found that plate-fin heat sinks with corrugated half-round pins in vertical arrangement subjected to parallel flow show better thermal performance over other configurations. Charles and Wang ${ }^{(2)}$ reported experimental results for natural convection heat transfer in three fin patterns viz. rectangular, trapezoidal and inverted trapezoidal of aluminium alloy. Authors found that heat transfer coefficient for inverted trapezoidal fin array is $10 \%$ and $25 \%$ higher than that of rectangular and normal trapezoidal fin design respectively. Kharche and Farkade ${ }^{(3)}$ reported experimental results for vertical rectangular finned array with and without notches. It was found that heat transfer rate of un-notched fins was less than the notched fins by about $18 \%$. Mohan et al. ${ }^{(4)}$ experimentally investigated heat transfer on plate fin heat exchangers with wavy fins. The authors derived general correlations for friction factor and colburn factor using multiple linear regression analysis. Higher heat transfer coefficient with reasonable pressure drop was observed by using wavy fins. Dahiyaet al. ${ }^{(5)}$ conducted numerical studies on heat transfer through micro channel heat sinks with three different inlet and outlet flow arrangements. The authors found highest heat transfer coefficient in divergent-convergent combination of heat sinks as compared to other combinations. Aggarwal et al. ${ }^{(6)}$ reported CFD studies on spiral micro-channel heat sink with different mass flow rates of fluids with two different flow arrangements. The authors found that there was decrease in pressure drop by $2.39 \%$ and temperature by $6.99 \%$ during entry of fluid at inner spiral as compared to that at the outer spiral. Jubear and Al- Hamadani ${ }^{(7)}$ reported experimentally and computationally that the fin height affects natural convection heat transfer performance of a rectangular plate fin array. Manikanda et al. ${ }^{(8)}$ reported experimental and computational studies on three types of pin-fin profiles viz. rectangular, elliptical and stepped pin-fins. The experiments were performed in vacuum environment so as to consider only radiation heat transfer. Thermal performance of elliptical shaped pin fins was found to be the best. Ghyadh et al. ${ }^{(9)}$ reported CFD studies on heat transfer through four types of pin fins, out of which three were perforated and one was solid. Perforated pin-fins showed better thermal performance as compared to solid one. Rao and Somkuwar ${ }^{(10)}$ reported CFD studies of natural convection heat transfer in three types of tapered fins with taper angles of $1^{\circ}, 2^{\circ}$ and $3^{\circ}$, subjected to different heating power. Fins with $2^{\circ}$ taper angle showed better heat transfer performance at all heat inputs than the remaining two types of fins.

From the detailed review of literature, it is found that the rate of heat transfer can be increased passively by increasing the surface area, by using the inserts, extended surfaces or fins. In the present work, an attempt is made to study and analyze heat transfer enhancement passively using un-notched and notched plate fins.

\section{Computational Methodology}

In the present work, computational studies are conducted to analyze performance of seven types of vertical plate fin arrays subjected to natural convection heat transfer. Three types of vertical plate fins viz. plain rectangular fin, rectangular fin with square notch and rectangular fin with semi-circular notch are used with their seven combinations. These seven combinations of plate fin arrays under consideration are: plain rectangular, rectangular square notched, rectangular semi-circular notched, rectangular inverted square notched, rectangular inverted semi-circular notched, hybrid rectangular square-semi-circular notched and hybrid rectangular inverted square-semi-circular notched.

3D CFD simulations of all seven combinations of plate fin arrays are performed using SolidWorks Flow Simulation 2019 ${ }^{(11)}$. SolidWorks Flow simulation is a finite finite-volume based CFD program that allows to model fluid flow using the NavierStokes's equations. This program is an add-on to the regular SolidWorks package that is used to generate the CAD model of the geometry.

\subsection{Details of fin geometries and base plate}

Size of each rectangular plain fin is: $80 \mathrm{~mm} \mathrm{X} 43 \mathrm{~mm} \mathrm{X} 2 \mathrm{~mm}$. Lengths and thicknesses of all types of fins are $80 \mathrm{~mm}$ and $2 \mathrm{~mm}$ respectively. The height of each vertical fin other than plain rectangular one is taken in such a way that surface areas of all seven types of fin geometries are same. By keeping the surface area constant for all fin arrays, its effect on convective heat transfer enhancement is nullified. Dimensions of the three mainly used fin geometries are presented inFigure 1. 

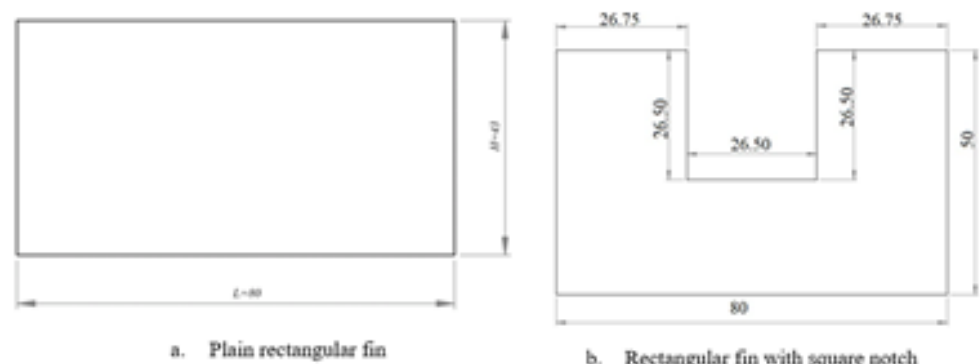

b. Rectangular fin with square notch

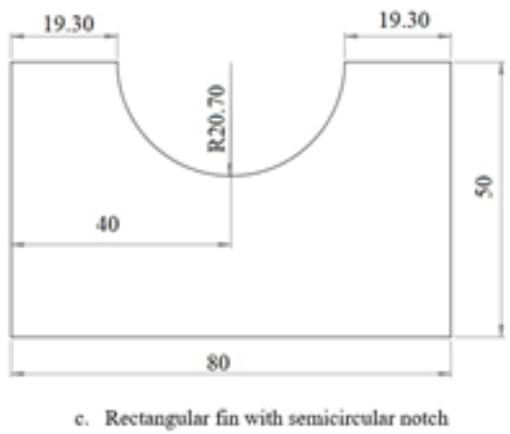

Fig 1.2D drawings of three plate fin geometries

3D CAD models of all seven types of fin geometries are prepared using SolidWorks 2019 software.Figure 2 shows solid models of the three main vertical plate fins used for the present study. All fins are fitted in the slots provided on the base plate. Material for the base plate is also considered to be aluminium. In each set of fin arrays, there are 11 fins, equally spaced on base plate of size $124 \mathrm{~mm}$ X $80 \mathrm{~mm}$ X $24 \mathrm{~mm}$.

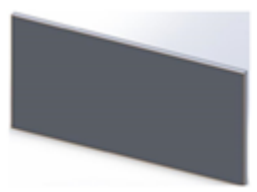

Plain rectangular fin

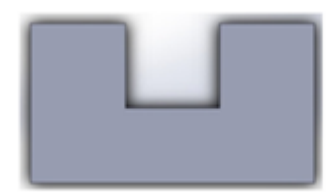

Square notched fin

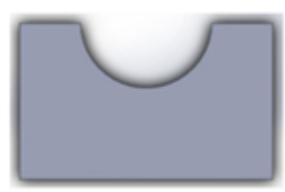

Semi-cireular notebed fin

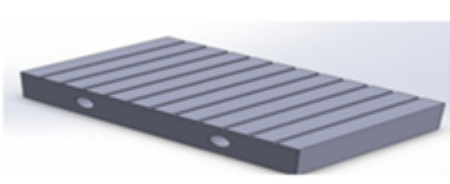

Base Plate

Fig 2. Solid models of three plate fins and base plate

\subsection{Geometry Creation and Meshing}

Mesh generation in SolidWorks Flow Simulation 2019 is accomplished by using Cartesian-based meshes that are independent of the model geometry. This technique generates cubic cells that are adjacent to each other as well as the boundary of the computational domain. The cells are also oriented along the Cartesian coordinates of the CAD geometry. Since Cartesianbased meshes cannot generally form fit to the surfaces of the geometry, partial cells consisting of fluid and solid volume will be generated at the fluid/solid boundary. The mesh can then be refined by splitting the cubic cells into a maximum of 8 similarly shaped cuboids to properly represent surface boundaries of the geometry. Since the CAD model is native to the program, it can easily identify solid edges or boundaries of the solid model and can then refine the mesh more accurately ${ }^{(12)}$. Figure 3 shows meshing of plain rectangular fin arrays. 


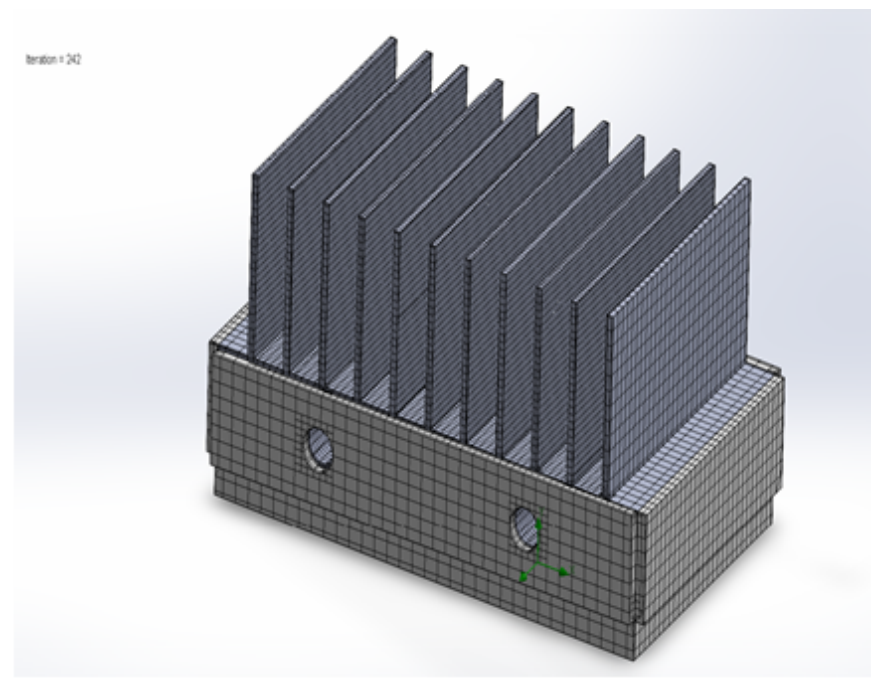

Fig 3. Meshing of plain rectangular fin array

\subsection{Governing equations \& boundary conditions}

After creating suitable dense mesh each individual cell or a control volume is ready for calculation. First, the area and normal vector direction for each face of each cell are calculated using the CAD geometry. Then the appropriate equations can be applied to each cell depending on their type fluid flow equations for fluidic cells, and heat conduction and direct electrical current for solid cells. Navier-Stokes's equations in the Cartesian coordinate system are used to formulate the fundamental conservation laws of mass, momentum, and energy ${ }^{(13)}$ :

Conservation of mass:

$$
\frac{\partial \rho}{\partial t}+\frac{\partial\left(\rho u_{i}\right)}{\partial x_{i}}=0
$$

At steady state, the first term in equation (1) will be zero hence, this equation reduces to

$$
\frac{\partial\left(\rho u_{i}\right)}{\partial x_{i}}=0
$$

Conservation of momentum:

$$
\frac{\partial\left(\rho u_{i}\right)}{\partial t}+\frac{\partial}{\partial x_{j}}\left(\rho u_{i} u_{j}\right)+\frac{\partial P}{\partial x_{i}}=\frac{\partial}{\partial x_{j}}\left(\tau_{i j}+\tau_{i j}^{R}\right)-\rho g_{i} \quad i=1,2,3
$$

Where, $\mathrm{u}$ is the fluid velocity, $\rho$ is the fluid density, and $\rho \mathrm{g}_{i}$ is buoyancy force per unit mass.

At steady state, in the absence of turbulence, equation (3) reduces to

$$
\frac{\partial}{\partial x_{j}}\left(\rho u_{i} u_{j}\right)+\frac{\partial P}{\partial x_{i}}=\frac{\partial}{\partial x_{j}}\left(\tau_{i j}\right)-\rho g_{i} \quad i=1,2,3
$$

Conservation of energy:

$$
\begin{gathered}
\frac{\partial \rho E}{\partial t}+\frac{\partial \rho u_{i} E}{\partial x_{i}}=\frac{\partial}{\partial x_{i}}\left(u_{j}\left(\tau_{i j}+\tau_{i j}^{R}\right)+q_{i}\right)+\frac{\partial p}{\partial t}-\tau_{i j}^{R} \frac{\partial u_{i}}{\partial x_{j}}+\rho \varepsilon+\rho g_{i} u_{i}+\dot{q}_{g e n} \\
E=h+\frac{u^{2}}{2}
\end{gathered}
$$


Where, $\mathrm{E}$ is energy, $\mathrm{h}$ is the thermal enthalpy, $\dot{q}_{g e n}$ is a heat source per unit volume, $\tau_{i j}$ is the viscous shear stress tensor, $\tau_{i j}^{R}$ is Reynolds-stress tensor, e is turbulent dissipation and $q_{i}$ is the diffusive heat flux.

For the present case of steady state energy transfer without turbulence, equation (5) reduces to

$$
\frac{\partial \rho u_{i} E}{\partial x_{i}}=\frac{\partial}{\partial x_{i}}\left(u_{j} \tau_{i j}+q_{i}\right)+\rho g_{i} u_{i}+\dot{q}_{g e n}
$$

For simulation of heat transfer through solid region, following energy conservation equation is used:

$$
\frac{\partial T}{\partial t} \rho C p=\frac{\partial}{\partial x_{i}}\left(k_{i} \frac{\partial T}{\partial x_{i}}\right)+\dot{q}_{g e n}
$$

Where, $\mathrm{Cp}$ is specific heat, $\dot{q}_{g e n}$ is specific heat release (or absorption) rate per unit volume, and $\mathrm{k}_{i}$ is the Eigen values of the thermal conductivity tensor.

At steady state, equation (8) change to,

$$
\frac{\partial}{\partial x_{i}}\left(k_{i} \frac{\partial T}{\partial x_{i}}\right)+\dot{q}_{g e n}=0
$$

While selecting the boundary conditions, heat source of $38.4 \mathrm{~W}$ is given at heater position in the base plate. The same wattage is provided while performing validation experiments with plain rectangular plate fin array. The other initial conditions as presented inFigure 4 are: pressure: $101325 \mathrm{~Pa}$, room temperature: $30^{\circ} \mathrm{C}$, initial velocity parameter in $\mathrm{X}, \mathrm{Y}, \mathrm{Z}: 0 \mathrm{~m} / \mathrm{s}(\mathrm{due}$ to natural convection), initial solid temperature: $30^{\circ} \mathrm{C}$, outer wall thermal conditions: adiabatic, surface roughness: 0 micrometer, heat conduction in solids: considered, conductivity type: isotropic, predefined solid: aluminium with thermal conductivity $\mathrm{k}=$ $235 \mathrm{~W} / \mathrm{mK}$ and mass density $\mathrm{r}=2689 \mathrm{~kg} / \mathrm{m}^{3}$ for all fin arrays and the base plate, asbestos cement sheet $(\mathrm{k}=0.58 \mathrm{~W} / \mathrm{mK}, \mathrm{Cp}=$ $840 \mathrm{~J} / \mathrm{kgK}$ ) as insulation at four side faces and one bottom face of the base plate, radiation heat transfer: not considered, time dependent nature: not considered, gravity: $0 \mathrm{~m} / \mathrm{s}^{2}$ along X and Y direction \& $-9.81 \mathrm{~m} / \mathrm{s}^{2}$ along Z direction. Default fluid: air, flow type: laminar.

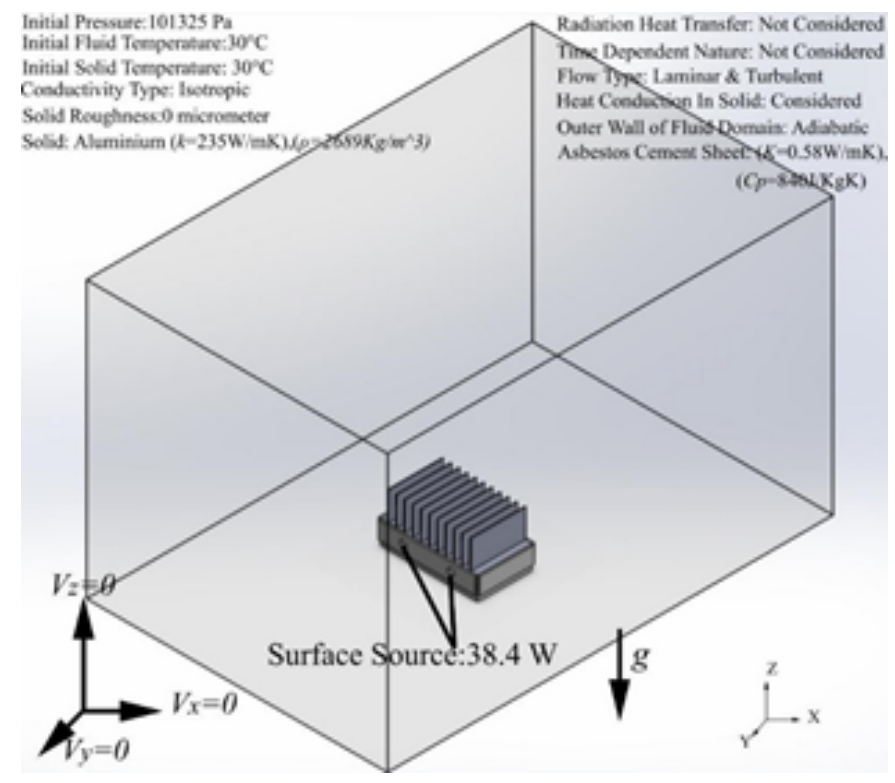

Fig 4. Initial and boundary conditions at plate fin arrays

SolidWorks Flow Simulation software provides multiple solver options such as Direct Sparse, Intel Direct Sparse, Large Problem Direct Sparse, and FFEPlus iterative solver. For the present simulation, FFEPlus iterative solver is selected which is a default solver option under automatic solver selection. This solver solves the set of algebraic equations using approximate technique viz. advanced matrix reordering. The solution is assumed and the associated errors are evaluated during each iteration ${ }^{(14)}$. The iterations continue till the errors become acceptable. For the present simulation, minimum error value set is $10^{-6}$ for accurate results. 


\section{CFD STUDIES ON PLAIN RECTANGULAR FIN ARRAYS}

During preprocessing, the 3D model of plain rectangular plate fin array is defined, meshing is performed and boundary conditions are set. During processing, solver is defined, a convergence criterion is set and the simulations are performed with the given initial and boundary conditions. The post processing includes deriving the results in the form of contours, vector plots and surface plots.Figure 5 reports wall temperature contours of plain plate fin array. The highest temperature of about $360 \mathrm{~K}$ is observed at the heater locations, at top surface of the base plate and also on the vertical faces of plate fins near the base. The lowest temperature of about $340 \mathrm{~K}$ is observed at outer the corners of the asbestos cement insulation surfaces. The horizontal insulation below the base plate has larger thickness $(9 \mathrm{~mm})$ as compared to the four vertical side insulations $(3 \mathrm{~mm})$. Hence, the temperatures at outer surface of lower insulation are lower as compared to those at the outer surface of side insulations (Figure 5).

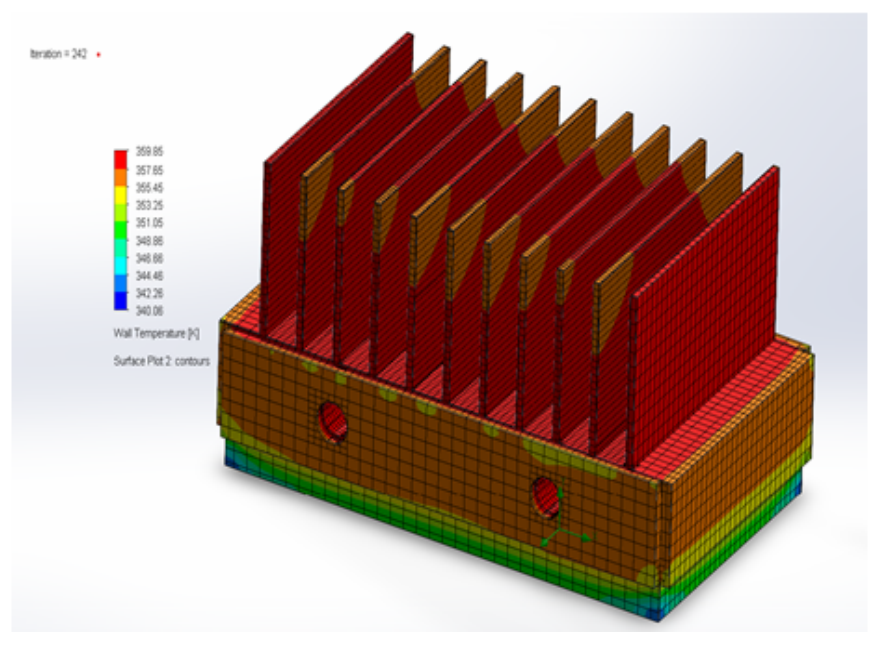

Fig 5. Wall temperature contours of plain plate fin array

Figure 6 shows air velocity flow trajectory for the plain vertical plate fin array. The variation in magnitude of velocity is found to be from about $0 \mathrm{~m} / \mathrm{s}$ near the base plate to about $0.4 \mathrm{~m} / \mathrm{s}$ just above the plate fins. Velocity vectors are found to move in upper direction from near the outer faces of insulations, through small passages between the vertical plates. The order of magnitude of the velocity vectors indicates laminar flow of plumes during natural convection.

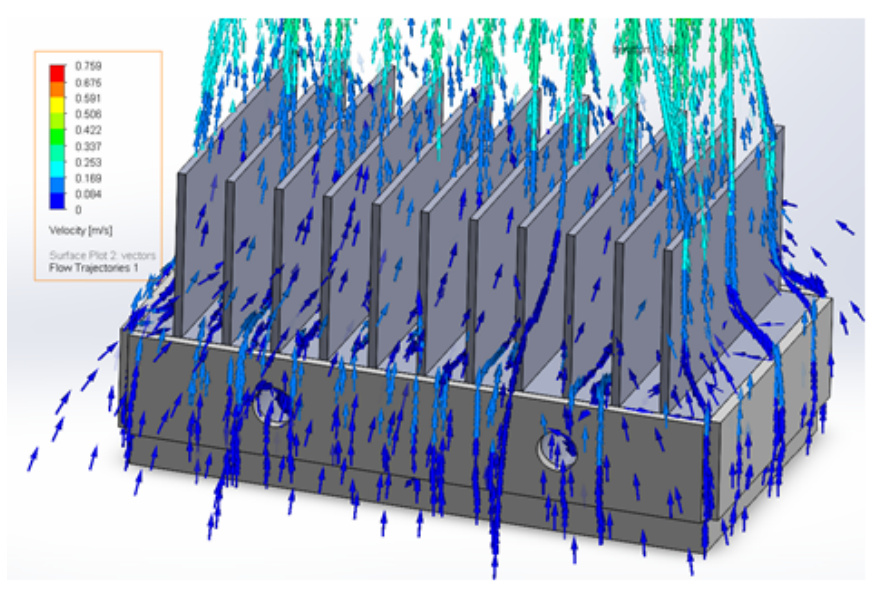

Fig 6. Air velocity flow trajectory of plain plate fin array

Figure 7 shows heat transfer coefficient contours for the plain vertical plate fin array. The lowest heat transfer coefficient of the order of $0 \mathrm{~W} / \mathrm{m}^{2} \mathrm{~K}$ is observed at the heater surface and also at the base plate. This is due to the negligible temperature 
difference between the hot surfaces and the local ambient temperature close these surfaces. The highest heat transfer coefficient of the order of $49 \mathrm{~W} / \mathrm{m}^{2} \mathrm{~K}$ is observed on the side faces of the vertical plate fins due to sufficient temperature difference the surface and the ambient. Also, natural convection currents in the form of plumes are prominently taking the heat away for these surfaces. The average heat transfer coefficient for the plate fin array is found to be $7.251 \mathrm{~W} / \mathrm{m}^{2} \mathrm{~K}$.

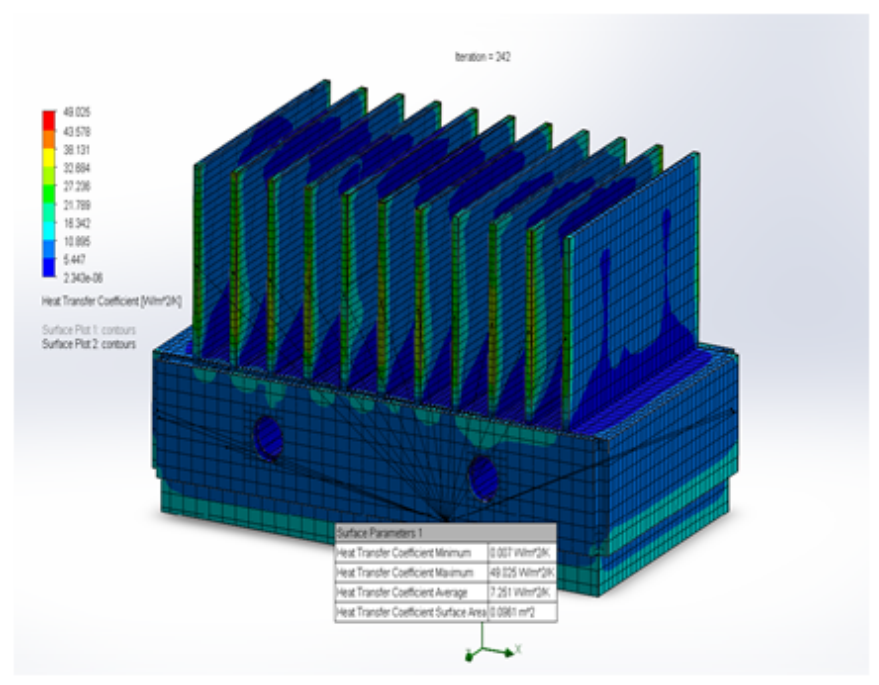

Fig 7. Heat transfer coefficient contours of plain plate fin array

The CFD results for the heat transfer coefficient at plain rectangular plate fin array are validated by comparing them with the available experimental results performed by the authors. Experiments are performed on the plain aluminium plate fin array subjected to constant heat flux condition by applying voltage of $60 \mathrm{~V}$ and corresponding current of $0.64 \mathrm{~A}$. The resulting input power available at resistance heaters is $38.4 \mathrm{~W}$. Temperatures are measured at the base of the fins, at the vertical surface as well as at the tip of the fins. Overall heat transfer coefficient is calculated using the concepts of fin efficiency and by using modified Rayleigh's equation $^{(15)}$. Heat lost by conduction through the insulating material from 5 sides of the base plate is considered. The resulting experimental value of heat transfer coefficient is $7.03 \mathrm{~W} / \mathrm{m}^{2} \mathrm{~K}$. Difference between the experimental and CFD result for heat transfer coefficient is about 3\% which is very small. Experimental result for heat transfer coefficient is smaller as compared to the corresponding computational result. The main reason behind this trend is neglect of radiative heat loss in computational studies, but in actual practice, there is always some radiative heat loss. Hence, the present CFD model used for simulation of natural convection heat transfer through plate fin array is found to be valid.

\section{CFD Studies on Remaining Combinations of Fin Arrays}

Using the same process that is used for simulation of plain rectangular fin array, 3D CFD simulations are performed on the remaining six combinations of plate fin arrays. These fin arrays include: rectangular square notched, rectangular semicircular notched, rectangular inverted square notched, rectangular inverted semi-circular notched, hybrid rectangular squaresemi-circular notched and hybrid rectangular inverted square-semi-circular notched. Once the simulations are complete, post processing is conducted to study variations in surface temperature, velocity and heat transfer coefficient for different plate fin arrays.

\subsection{Wall Temperature Contours}

Figure 8 shows wall temperature contours for six combinations of plate fin arrays. For all combinations of fin arrays, the lower limit of temperature is about $341 \mathrm{~K}$ for inverted square notched fin arrangement (Figure $8 \mathrm{c}$ ) where as about $343.5 \mathrm{~K}$ for hybrid square-semicircular notched fin array (Figure 8e). The upper limit of temperature is about $355 \mathrm{~K}$ for inverted semicircular notched fin arrangement (Figure $8 \mathrm{~d}$ ) where as about $359.5 \mathrm{~K}$ for hybrid square-semicircular notched fin array (Figure 8e). Major fin surface of hybrid square-semicircular notched array is subjected to higher temperature as compared to other fin arrays. Average fin surface temperatures of inverted notched fin arrays are found to be lower as compared with the normal fin arrays. Here, surface temperature of hybrid square-semicircular notched array (Figure 8f) is found to be the lowest, which is 
followed by remaining two notched fin arrays (Figure 8a, b). The main reason behind lower temperatures at the fin surfaces in case of inverted fin arrays might be due to the free flow of air through the notch cavities near the base plate.

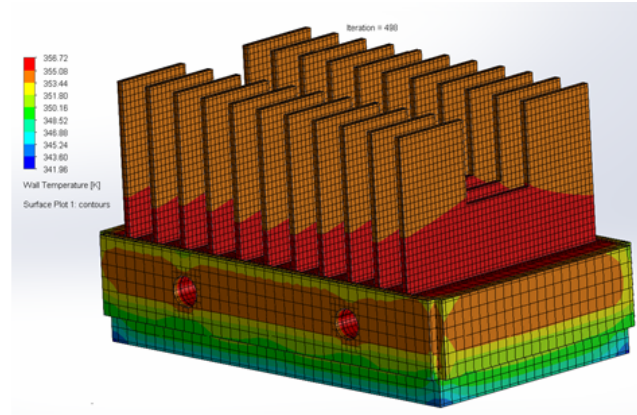

a. Square notched fin array

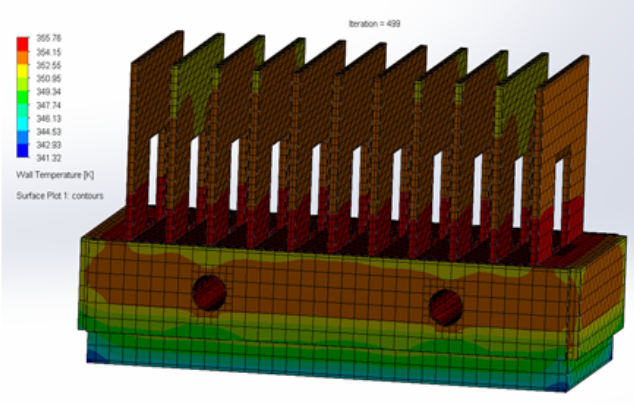

c. Inverted square notched fin array

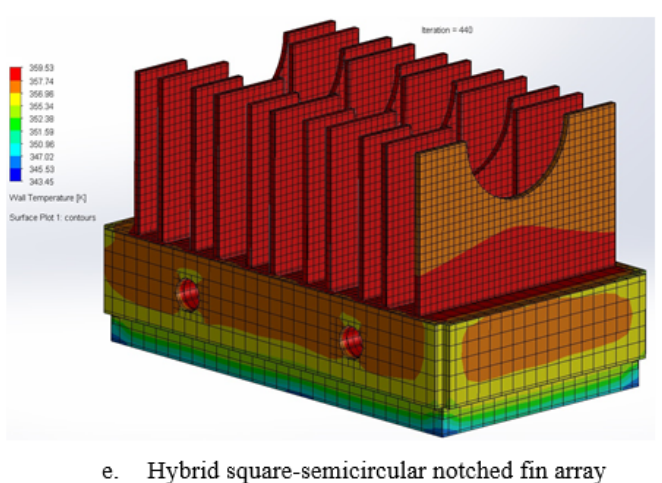

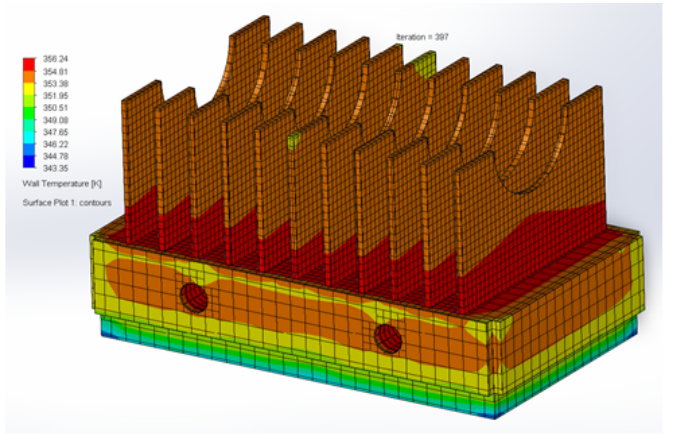

b. Semi-circular notched fin array

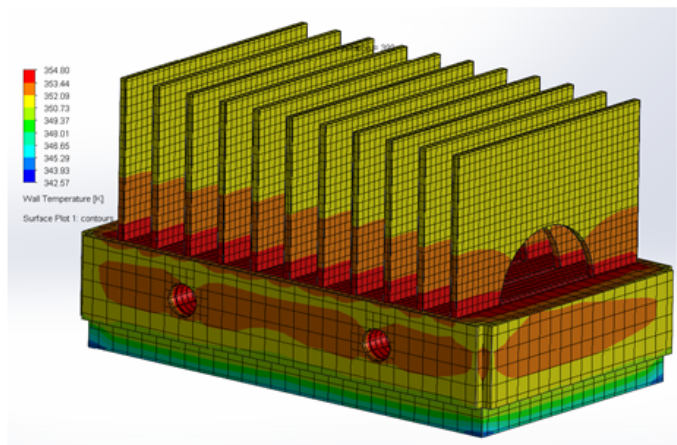

d. Inverted semi-circular notched fin array

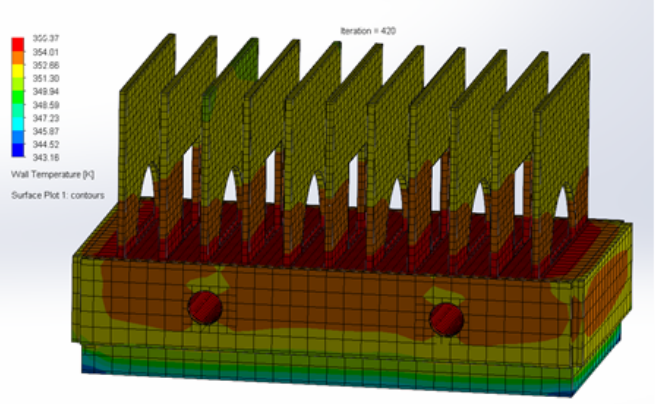

f. Inverted hybrid square-semicircular notched fin array

Fig 8. Wall temperature contours for six combinations of plate fin arrays

\subsection{Air Velocity Flow Trajectories}

Figure 9 shows air velocity flow trajectories for six combinations of plate fin arrays. In all combinations, the minimum air velocity is observed to be $0 \mathrm{~m} / \mathrm{s}$. The maximum air velocity of $0.772 \mathrm{~m} / \mathrm{s}$ is found for square notched fin array (Figure 9a). This is followed by air velocity of $0.756 \mathrm{~m} / \mathrm{s}$ for semi-circular notched fin array (Figure $9 \mathrm{~b}$ ), $0.755 \mathrm{~m} / \mathrm{s}$ for inverted hybrid squaresemicircular notched fin array (Figure 9f), $0.748 \mathrm{~m} / \mathrm{s}$ for Inverted square notched fin array (Figure 9c), $0.737 \mathrm{~m} / \mathrm{s}$ for inverted semi-circular notched fin array (Figure 9d) and $0.725 \mathrm{~m} / \mathrm{s}$ for hybrid square-semicircular notched fin array (Figure 9e). In all inverted combinations of fin arrays, air plumes flow not only between the two adjacent plate fins but also through the notch portion near base plate. These plumes effectively carry away heat through natural convection resulting in lower fin temperatures and higher heat transfer coefficients. 


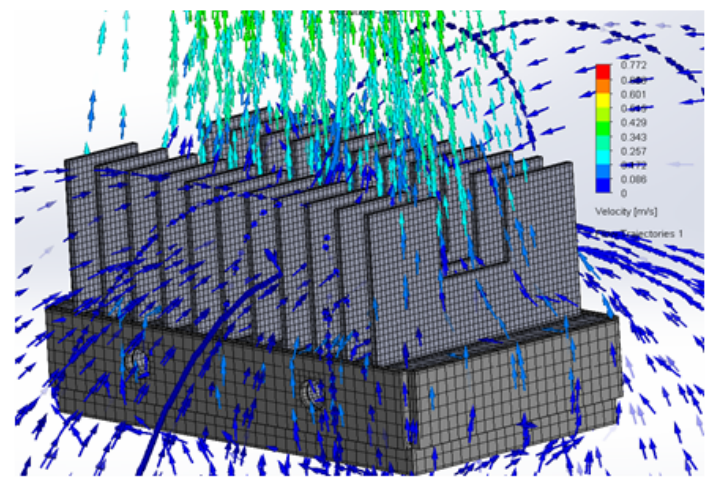

a. Square notched fin array

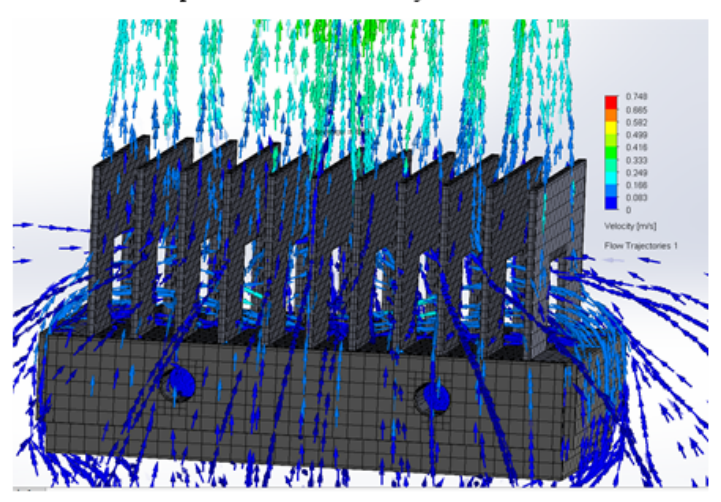

c. Inverted square notched fin array

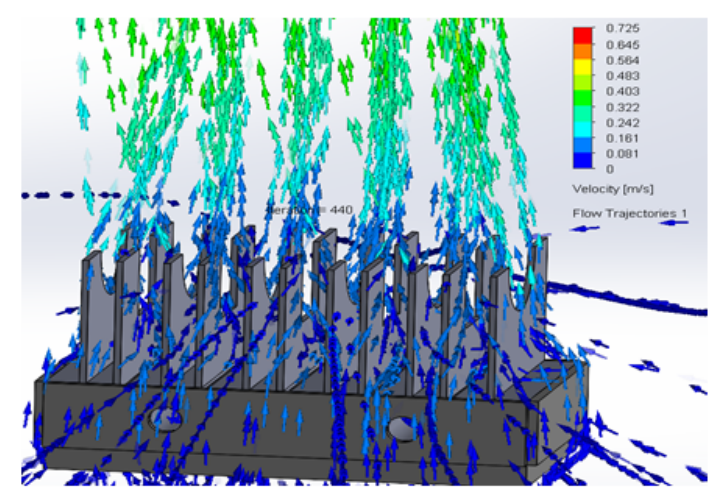

e. Hybrid square-semicircular notched fin array

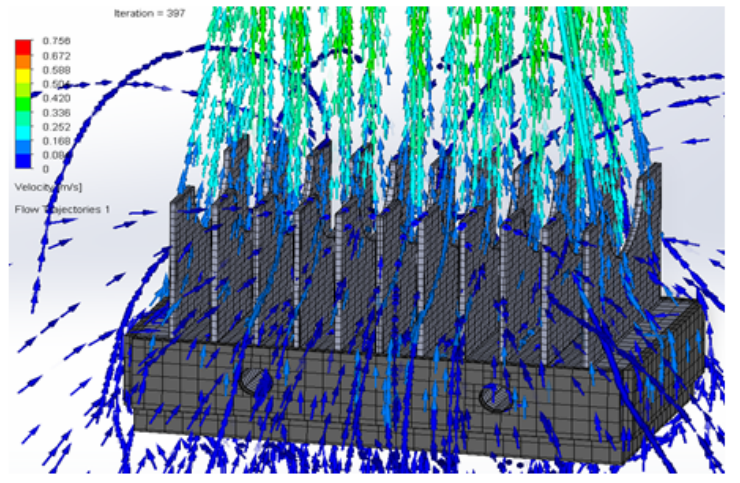

b. Semi-circular notched fin array

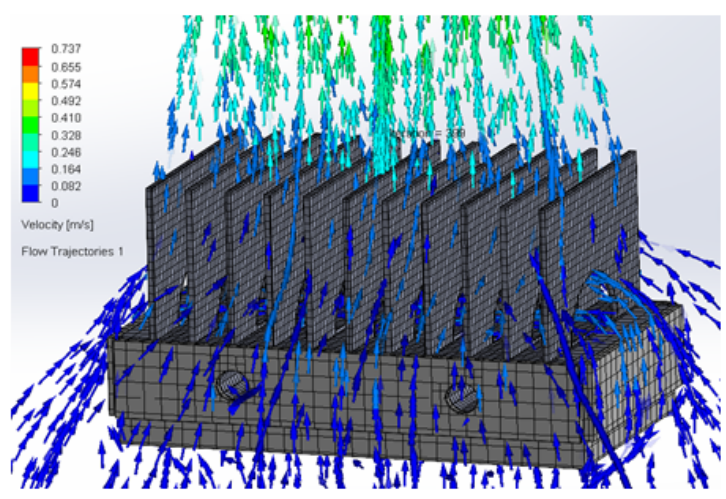

d. Inverted semi-circular notched fin array

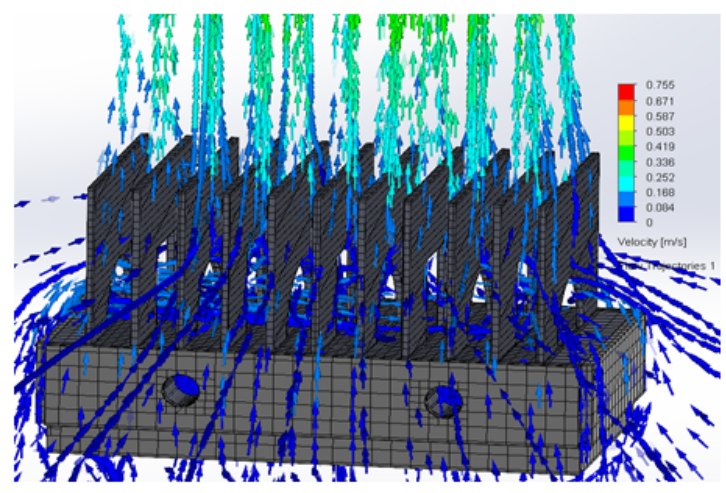

f. Inverted hybrid square-semicircular notched fin array

Fig 9. Air velocity flow trajectories for six combinations of plate fin arrays

\subsection{Heat Transfer Coefficient Contours}

Figure 10 shows heat transfer coefficient contours for six combinations of plate fin arrays. The highest average heat transfer coefficient of $7.82 \mathrm{~W} / \mathrm{m}^{2} \mathrm{~K}$ is found to be for inverted hybrid square-semicircular notched fin array (Figure 10f). The decreasing order of average heat transfer coefficient values for different plate fin arrays are: $7.63 \mathrm{~W} / \mathrm{m}^{2} \mathrm{~K}$ for inverted square notched fin array (Figure 10c), $7.53 \mathrm{~W} / \mathrm{m}^{2} \mathrm{~K}$ for hybrid square-semicircular notched fin array (Figure $10 \mathrm{e}$ ), $7.47 \mathrm{~W} / \mathrm{m}^{2} \mathrm{~K}$ for inverted semicircular notched fin array (Figure $10 \mathrm{~d}$ ), $7.43 \mathrm{~W} / \mathrm{m}^{2} \mathrm{~K}$ for semicircular notched fin array (Figure $10 \mathrm{~b}$ ) and $7.1 \mathrm{~W} / \mathrm{m}^{2} \mathrm{~K}$ for square notched fin array (Figure 10a). 


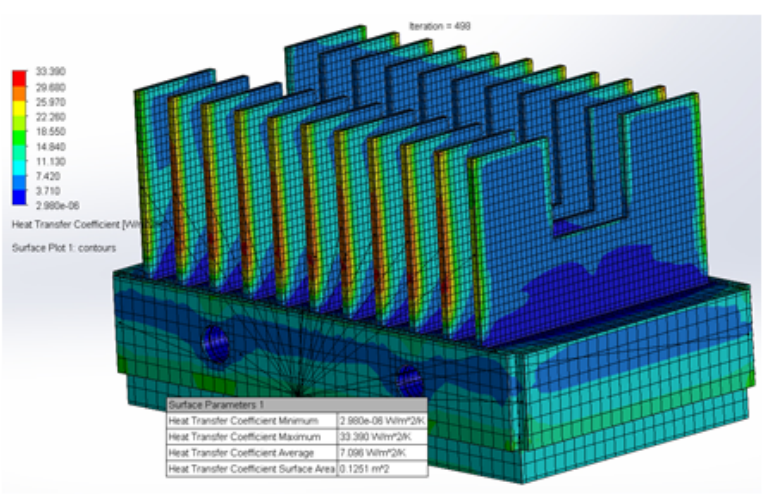

a. Square notched fin array

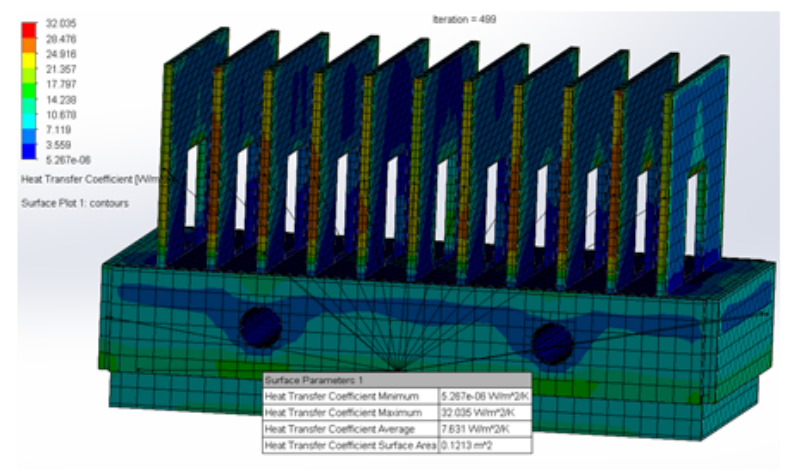

c. Inverted square notched fin array

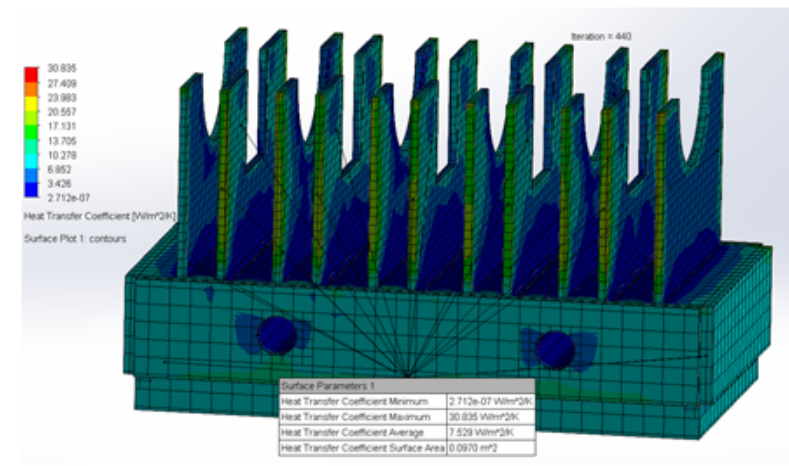

e. Hybrid square-semicircular notched fin array

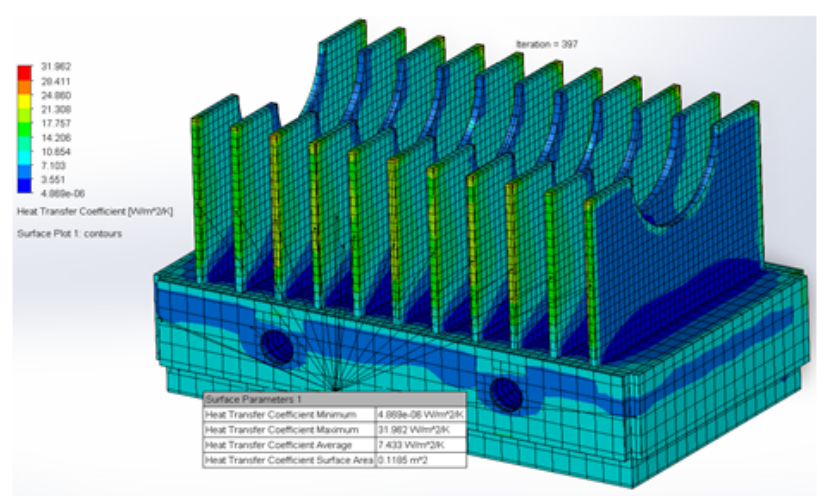

b. Semi-circular notched fin array

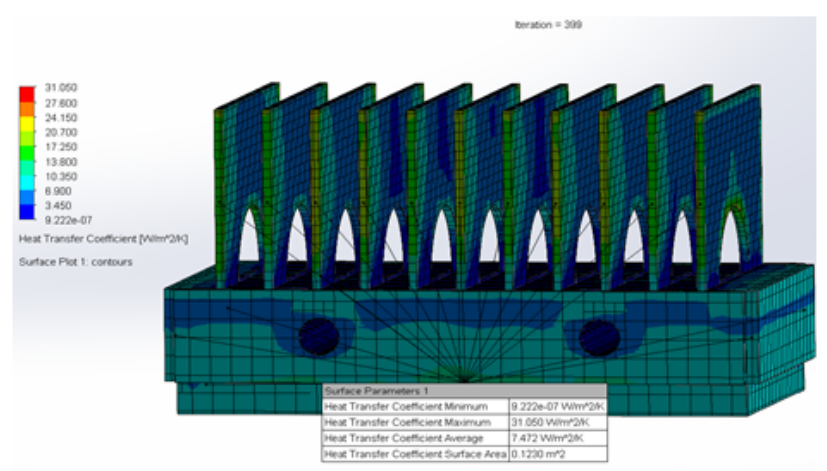

d. Inverted semi-circular notched fin array

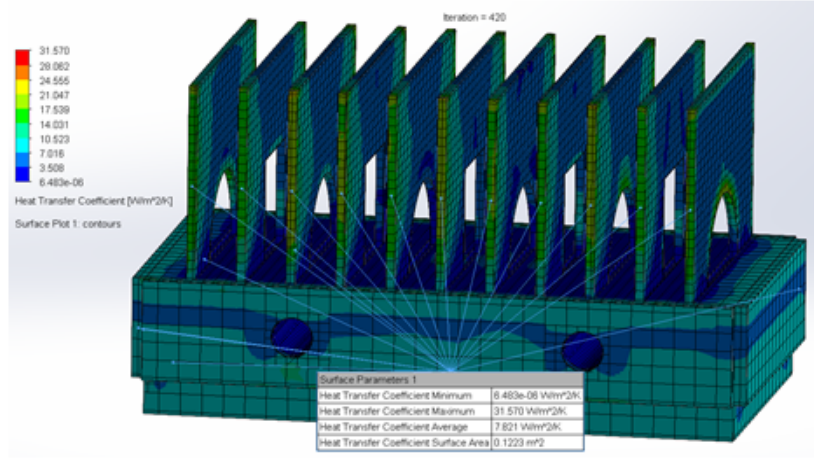

f. Inverted hybrid square-semicircular notched fin array

Fig 10. Heat transfer coefficient contours for six combinations of plate fin arrays

Average heat transfer coefficients for inverted plate fin array combinations are high as compared with the non-inverted combinations. Also, hybrid plate fin arrays, whether inverted or not, show higher heat transfer coefficient values as compared with uniform notched fin arrays. These results highlight importance of inverted hybrid fin arrays for effectively transferring the heat from the heat sinks by natural convection (Figure 11). 


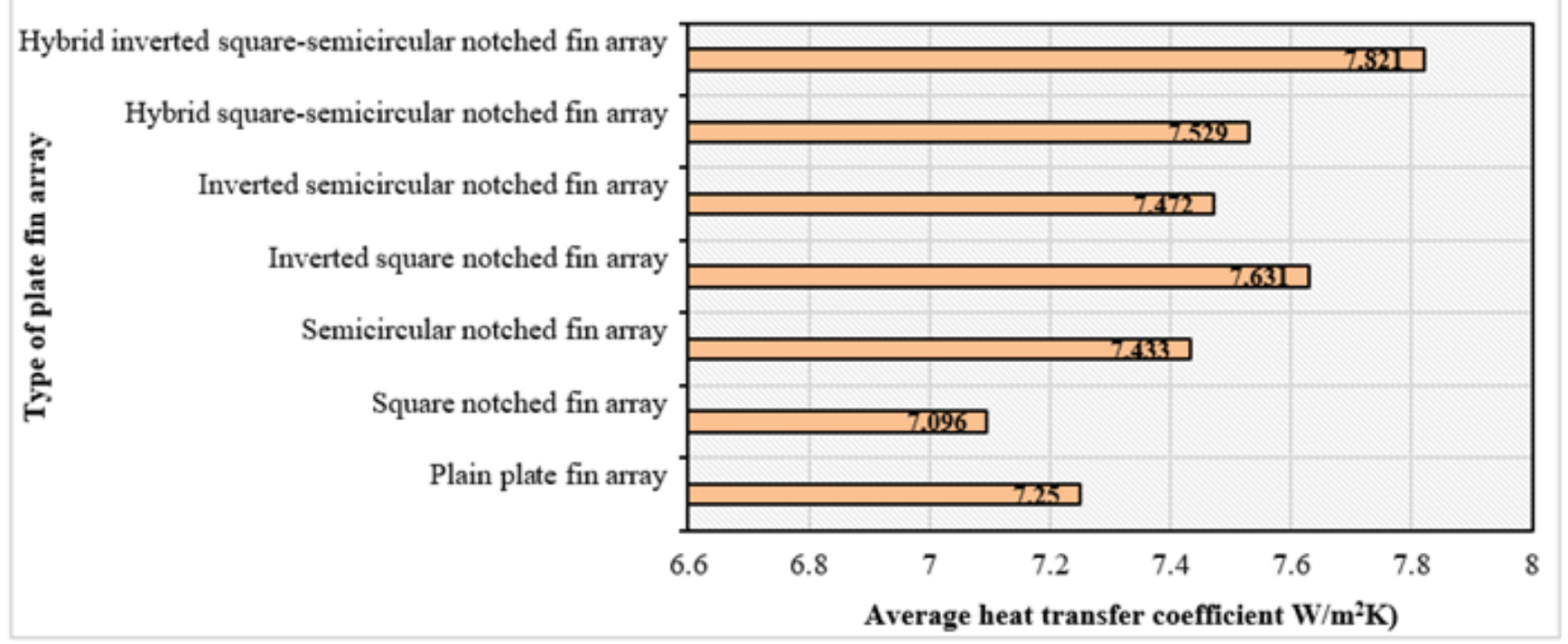

Fig 11. Average heat transfer coefficients for all combinations of plate fin arrays

\section{Conclusion}

In the present work, computational studies are conducted on seven types of vertical plate fin array combinations. SolidWorks Flow Simulation software is used for conducting this research. Computational studies can be effectively used to reduce expenses on additional experimentation.

3D CFD simulation is first conducted on plain vertical plate fin array. Computational value of average heat transfer coefficient is found to be $7.251 \mathrm{~W} / \mathrm{m}^{2} \mathrm{~K}$, which is about $3 \%$ higher than the corresponding experimental value i.e. $7.03 \mathrm{~W} / \mathrm{m}^{2} \mathrm{~K}$.The main reason behind lower experimental value is neglect of radiative heat loss in computational studies, but in actual practice, these is always some radiative heat loss.

Among all fin combinations, the highest average heat transfer coefficient of $7.82 \mathrm{~W} / \mathrm{m} 2 \mathrm{~K}$ is found to be for inverted hybrid square-semicircular notched fin array. Average heat transfer coefficients for inverted plate fin array combinations are high as compared with the non-inverted combinations.

Hybrid plate fin arrays, whether inverted or not, show higher heat transfer coefficient values in most of the cases as compared with uniform notched fin arrays.

Rectangular plain plate fin array shows higher heat transfer coefficient as compared to the rectangular plate fin array with square notches for the same operating conditions. That is, providing notches on plain geometry might not be sometimes feasible for heat transfer enhancement.

Limitations and future scope: The CFD results obtained in the present work are validated only for plain plate fin array. Detailed experiments can be performed on remaining six combinations of the plate fin arrays and the experimental results can be compared with the CFD results obtained in the present work. Also, all experiments can be performed at different input power values so as to investigate their effect on natural convection heat transfer in all combinations of plate fin arrays.

\section{References}

1) Freegah B, Hussain AA, Falih AH, Towsyfyan H. CFD analysis of heat transfer enhancement in plate-fin heat sinks with fillet profile: Investigation of new designs. Thermal Science and Engineering Progress. 2020;17(100458). Available from: https://dx.doi.org/10.1016/j.tsep.2019.100458.

2) Charles R, Wang CC. A novel heat dissipation fin design applicable for natural convection augmentation. International Communications in Heat and Mass Transfer. 2014;59:24-29. Available from: https://dx.doi.org/10.1016/j.icheatmasstransfer.2014.10.014.

3) Shivdas SK, Farkade HS. Heat transfer analysis through fin array by using natural convection. International Journal of Emerging Technology and Advanced Engineering. 2012;2(4):595-598.

4) Mohan D, Moorthy KS, Sivam SPSS, Rajendrakumar S. Experimental Investigation of Heat Transfer Study on Plate Fin Heat Exchangers with Wavy Fins. Indian Journal of Science and Technology. 2016;9(37):1-4. Available from: https://dx.doi.org/10.17485/ijst/2016/v9i37/94627. 
5) Dahiya A, Sehgal SS, Singh H. CFD and Heat Transfer Analysis of Microchannel Heat Sink with Different Inlet and Outlet Flow Arrangements. Indian Journal of Science and Technology. 2016;9(36):1-5. Available from: https://dx.doi.org/10.17485/ijst/2016/v9i36/101406.

6) Aggarwal V, Kalsi B, Sehgal SS. Computational Heat Transfer Analysis in Spiral Micro-Channel Heat Sink. Indian Journal of Science and Technology. 2016;9(36):1-8. Available from: https://dx.doi.org/10.17485/ijst/2016/v9i36/101488.

7) Abbas JJ, Aa AH. The effect of fin height on free convection heat transfer from rectangular fin array. International Journal of Recent Scientific Research. 2015;6(7):5318-5341. Available from: http://recentscientific.com/sites/default/files/3017.pdf.

8) Prabu NM, Venkateshwaran P, Murali G. Heat Transfer Analysis of Pin-fin Profiles for Aerospace Application using CFD. Research Square. 2021. Available from: https://doi.org/10.21203/rs.3.rs-444406/v1.

9) Ghyadh N, Abdulhadi, Ahmed MASASS, Baghdadi. Enhancement of Forced Convection Heat Transfer from Cylindrical Perforated Fins Heat Sink-CFD Study. Journal of Mechanical Engineering Research and Developments. 2021;44(3):407-419. Available from: https://jmerd.net/Paper/Vol.44,No.3(2021) 1407-419.pdf.

10) Rao AK, Somkuwar V. Heat transfer of a tapered fin heat sink under natural convection. Materials Today: Proceedings. 2021. Available from: https://dx.doi.org/10.1016/j.matpr.2021.02.565.

11) Planchard CD. SOLIDWORKS ${ }^{\circledR}$ Flow Simulation. Dassault Systemes SolidWorks Corporation. 2020.

12) Sean F. Numerical Analysis of an Electrical Transformer with Fins and Horizontal Pins. 2018. Available from: https://digitalscholarship.unlv.edu/ thesesdissertations/3251/.

13) Sobachkin A, Dumnov G. Numerical Basis of CAD-Embedded CFD. NAFEMS World Congress. 1920. Available from: https://openlab.citytech.cuny.edu/ swansonmech3550fa2018/files/2019/04/Flow_Basis_of_CAD_Embedded_CFD_Whitepaper.pdf.

14) 1995-2021 Dassault Systèmes. 1995. Available from: https://help.solidworks.com/2016/english/SolidWorks/cworks/c_Analysis_Solvers.htm?format=P\& value $=$.

15) Terekhov VI, Ekaid AL, Yassin KF. Laminar free convection heat transfer between vertical isothermal plates. Journal of Engineering Thermophysics. 2016;25(4):509-519. Available from: https://dx.doi.org/10.1134/s1810232816040081. 